\title{
Por que ler (apenas) os clássicos?
}

\author{
Why (only) read the classics?
}

PARADA, Maurício (org.). Os historiadores: clássicos da história. Vol. 1: de Heródoto a Humboldt. Petrópolis: Vozes/PUC-Rio, 2012, 302 p.

PARADA, Maurício (org.). Os historiadores: clássicos da história. Vol. 2: de Tocqueville a Thompson. Petrópolis: Vozes/PUC-Rio, 2013, 324 p.

\section{Fábio Duarte Joly}

joly@uol.com.br

Professor adjunto

Universidade Federal de Ouro Preto

Rua do Seminário, s/n.

35420-000 - Mariana - MG

Brasil

\section{Palavras-chave}

Historiografia; Historiografia antiga; Historiografia do século XIX.

Keywords

Historiography; Ancient historiography; $19^{\text {th }}$ century historiography. 
Os historiadores: clássicos da história, coletânea organizada por Maurício Parada, professor da Pontifícia Universidade Católica do Rio de Janeiro, consiste de quatro volumes, sendo que os dois primeiros estão agora disponíveis ao público. O primeiro volume inclui Heródoto, Tucídides, Políbio, Tito Lívio, Tácito, Flávio Josefo, Lorenzo Valla, Francesco Guicciardini, Jean Bodin, Giambattista Vico, Johann G. Herder, Edward Gibbon, Edmund Burke e Wilhelm von Humboldt. O segundo volume cobre Alexis de Tocqueville, Johann G. Droysen, Jules Michelet, Leopold von Ranke, Jacob Burckhardt, Karl Marx, Benedetto Croce, Robin G. Collingwood, Johan Huizinga, Henri Pirenne, Lucien Febvre, Marc Bloch, Fernand Braudel e Edward P. Thompson. O terceiro volume abarcará Paul Ricoeur, Jean-Pierre Vernant, Eric Hobsbawm, Emanuel Le Roy Ladurie, Georges Duby, Reinhart Koselleck, Jacques Le Goff, Marc Ferro, François Furet, Hayden White, Peter Burke, Pierre Nora, Carlo Guinzburg, Robert Darnton e Roger Chartier. Por fim, o quarto volume será dedicado ao Brasil: Primeiros relatos, Francisco Adolfo de Varnhagen, João Francisco Lisboa, Joaquim Nabuco, João Capistrano de Abreu, Oliveira Vianna, Manuel de Oliveira Lima, Manoel Bonfim, Afonso de E. Taunay, Luís da Câmara Cascudo, Otávio Tarquínio de Sousa, Serafim Soares Leite, Gilberto Freyre, Sérgio Buarque de Holanda, Caio Prado Júnior, Nelson Werneck Sodré e José Honório Rodrigues.

Como se vê, é uma bem-vinda iniciativa, pautada pelo objetivo de incluir um vasto leque de nomes que teorizaram e/ou escreveram história, e soma-se assim a outras coletâneas já publicadas a respeito. ${ }^{1}$

Os capítulos, em geral elaborados por especialistas nos autores escolhidos, estruturam-se a partir da apresentação do "historiador e seu tempo", "percursos e influências" e "conceitos-chave". Percebe-se uma preocupação do organizador em conferir unidade de método na montagem dos livros, tornando sua leitura mais proveitosa na medida em que facilita comparações entre os autores tratados.

De fato, um aspecto positivo da coletânea é a possibilidade de diálogo que se estabelece entre os capítulos visto, que são mencionadas as aproximações ou distanciamentos de um autor a outro. Para citar apenas alguns exemplos: a contraposição entre Tucídides e Heródoto, a influência de Tucídides no historiador judeu Flávio Josefo, a retomada da historiografia greco-romana por um humanista como Lorenzo Valla, a influência de Vico em Michelet, Croce e Collingwood, o impacto da história cultural de Burckhardt na obra de Huizinga, os contatos entre Pirenne, Febvre e Bloch, e a recepção das ideias de Marx em Croce e Thompson. Nos dois volumes iniciais da coletânea, o leitor constrói, portanto, a partir da variedade de autores e temas, a sua visão acerca de um encadeamento nas formas de pensar a história, da Antiguidade ao século XX.

Todavia, se, por um lado, este é um aspecto louvável da obra, por outro lado, não há como nos esquivar de questionar, numa resenha, alguns limites dessa empresa e que remetem, em última instância, à própria definição do que é clássico. Mesmo o organizador mostra-se ciente dessa questão quando, na apresentação, assevera que "a seleção de historiadores que apresentamos ao

\footnotetext{
${ }^{1}$ Por exemplo: LOPES 2007; LOPES; MUNHOZ 2010; BENTIVOGLIO; LOPES 2013.
} 
final desse projeto foi fruto de muitas dúvidas" (PARADA 2012, p. 7). Queria agora me juntar a ele para também exprimir as minhas dúvidas, já que não são apresentados os critérios para tal seleção ou mesmo uma definição mais circunscrita de "clássico", além da citação de Ítalo Calvino, de que "um clássico é o livro ou autor que nunca terminou o que tinha para dizer" (PARADA 2012, p. 7; cf. CALVINO 2007, p. 7).

O primeiro ponto que chama a atenção é o salto que se observa entre Flávio Josefo (século I d.C.) e Lorenzo Valla (século XV). Esse hiato de quase catorze séculos é uma significativa indicação do que se pressupõe por "clássico" pois descarta a historiografia da Antiguidade Tardia e o conjunto das obras históricas medievais. É possível fazer uma crítica dessa escolha a partir de artigos constantes na própria coletânea. Em sua contribuição sobre Valla, Mônica Vitorino acaba por indicar como essa perspectiva aceita o entendimento que os humanistas tinham do passado medieval:

\begin{abstract}
A historiografia medieval é marcada por uma perspectiva providencial e voltada a uma dimensão ultraterrena, enquanto os humanistas consideram a história como produto das ações humanas, atribuindo a ela uma função paradigmática e educativa. Enquanto os textos medievais eram crônicas áridas, sem grandes pretensões artísticas e redigidos nas línguas vernáculas locais, a nova historiografia era escrita em latim e utilizava os recursos estilísticos dos historiadores clássicos, principalmente Salústio e Tito Lívio (PARADA 2012, p. 139).
\end{abstract}

Por sua vez, essa concepção embasará aquela interpretação que Felipe Charbel analisa e critica no artigo sobre Guicciardini, qual seja, de que a produção dos humanistas italianos dos séculos XIV e XV foi "entendida teleologicamente como unidade heurística concebida a posteriori e geneticamente como 'marco zero' da modernidade em história, [...] como o momento em que a consciência histórica começa a adquirir forma, como consciência de si mesma" (PARADA 2012, p. 154), prefigurando os fundamentos da ciência histórica do século XIX.

Hoje, tende-se justamente a relativizar essa ruptura radical iniciada pelo humanismo no tocante à escrita da história. Nas palavras de Erich Cochrane (1981, p. XV), "os historiadores renascentistas deviam muito mais a seus predecessores medievais do que poderia parecer pela sua consciente rebelião contra os mesmos". E, para continuar com exemplos retirados da coleção sob análise, convém citar ainda o artigo sobre Huizinga, de autoria de Marcelo da Costa, que enfatiza a novidade da obra do medievalista holandês que se indagava sobre as continuidades e transformações que mais aproximam do que separam Idade Média e Renascença (PARADA 2013, p. 185).

Embora as coletâneas sobre historiadores publicadas no Brasil concedam grande e merecido espaço a medievalistas (sobretudo aos franceses ligados aos Annales - Bloch, Le Goff, Duby, Le Roy Ladurie - e a Pirenne), não há qualquer menção à historiografia medieval, alvo de recorrentes estudos no exterior desde os anos de 1950, reveladores de um quadro mais variegado e sofisticado dessa 
produção do que nossa percepção de "clássico" permite supor. ${ }^{2}$ A par dessa inclusão da historiografia medieval, penso ainda em se contemplar historiadores da Antiguidade Tardia, um período atualmente dissociado das ideias de crise e declínio (cf. BOWERSOCK; BROWN; GRABAR 2001) que sustentavam a qualificação das obras literárias desse momento como decadentes em contraposição a escritores anteriores como Salústio, Tito Lívio e Tácito. Por que não mencionar Amiano Marcelino, cujas Res Gestae pretendiam oferecer uma história desde 96 até 378, continuando assim do ponto onde Tácito parou com suas Histórias? E a tradição dos breviários que tem, em Eutrópio, um de seus representantes ao compor uma história romana, de Rômulo à morte de Joviano em 364? (ROHRBACHER 2003).

No que diz respeito às continuidades e rupturas historiográficas entre a Antiguidade Tardia e a Alta Idade Média, poderiam ser explorados, por exemplo, nomes ligados à tradição da "história universal", avançada por Eusébio de Cesareia (260-339), com sua História Eclesiástica. Posteriormente, ela influenciaria uma tradição histórica semelhante no Ocidente latino - como testemunham a Crônica de Jerônimo (347-419), uma tradução latina e adaptação da História de Eusébio, e a História contra os Pagãos, de Paulo Orósio (século V) - e que se propagou no Medievo, como revelam as Histórias de Frechulf de Lisieux, à época carolíngia (ALLEN 2003).

Agora, mesmo considerando o arco de tempo coberto pela coletânea, notam-se ausências de alguns pensadores que, se estivessem presentes, complementariam a seleção escolhida. Refiro-me, por exemplo, ao caso de Salústio, uma das principais influências de Tácito (como lembra o artigo de Juliana B. Marques), e àquele dos iluministas franceses, que nos artigos sobre Herder, Gibbon, Burke e Tocqueville aparecem - em especial Montesquieu e Voltaire - como referências importantes. Hegel é outra figura ausente e um artigo sobre sua filosofia da história contribuiria para incrementar conexões com os artigos sobre Marx e Droysen.

Mas essas ausências são justificáveis tendo em vista a necessidade de se fazer recortes. Cito-as aqui apenas como complementos possíveis já que também são considerados clássicos, e a coletânea não abarca somente aqueles tidos como historiadores em sentido estrito, mas os que pensaram em termos de filosofia da história, teoria da historiografia e filosofia política. Gostaria de continuar a chamar a atenção sobre o ganho que teríamos caso fossem projetadas coletâneas que incluíssem autores não-canônicos, muitas vezes citados como contraponto àqueles tidos por clássicos e, portanto, também relevantes. No artigo de Michelle Schreiner sobre Michelet vemos como esse historiador francês se remete a outros historiadores contemporâneos seus como Augustin Thierry e François Guizot para propor sua maneira de encarar a história (PARADA 2013, p. 59) e, quando José Carlos Reis escreve sobre Marc Bloch, nota, ao final, o débito desse medievalista com Fustel de Coulanges (PARADA 2013, p. 273). E pode-se

${ }^{2}$ Ver DELIYANNIS 2003, p. 1-13 para um panorama dos temas e gêneros literários da historiografia medieval, e seu tratamento pela crítica moderna. 
mencionar também a tradição antiquária dos séculos XVII e XVIII, combatida pela história filosófica, mas, como apontou Momigliano, não inteiramente divorciada dela como revela a obra de Gibbon (2004, p. 112).

Contudo, em se procedendo assim, estaríamos questionando o significado de "clássico" sem ainda alterar seu conteúdo europeu, restrito, sobretudo, a Alemanha, França, Inglaterra e Itália. Perde-se uma visão global e intercultural, cuja necessidade tem sido enfatizada por estudiosos que propõem a análise das variedades de pensamento histórico em diferentes contextos ao longo do tempo, ocidentais ou não (como no caso das tradições islâmica, chinesa, indiana e africana) (RÜSEN 2002; WANG; IGGERS 2002), quebrando aquela sequência linear dos gregos à Europa oitocentista na constituição da ciência histórica. Enfim, parece que hoje está em disputa a própria noção de "clássico".

Reitero que as considerações acima não invalidam o projeto de Os historiadores: clássicos da história. Seu mérito reside não apenas no esforço de reunir um time de especialistas para tratar de 28 historiadores nos dois primeiros volumes da coleção. Porém, contribui, sobretudo, para gerar reflexões sobre as formas tradicionais de organizarmos a história do pensamento histórico, apontando a possibilidade de outros caminhos.

\section{Referências bibliográficas}

ALLEN, Michael I. Universal History 300-1000: origins and Western developments. In: DELIYANNIS, Deborah Mauskopf (ed.). Historiography in the Middle Ages. Leiden: Brill, 2003.

BENTIVOGLIO, Julio; LOPES, Marcos Antônio (orgs.). A constituição da História como ciência: de Ranke a Braudel. Petrópolis: Vozes, 2013.

BOWERSOCK, Glen W.; BROWN, Peter; GRABAR, Oleg (eds.). Interpreting Late Antiquity: essays on the postclassical world. Cambridge, Mass.: Harvard University Press, 2001.

CALVINO, Italo. Perché leggere i classici. Milano: Oscar Mondadori, 2007 [1981].

COCHRANE, Eric. Historians and historiography in the Italian Renaissance.

Chicago: The University of Chicago Press, 1981.

DELIYANNIS, Deborah Mauskopf (ed.). Historiography in the Middle Ages. Leiden: Brill, 2003.

LOPES, Marcos Antônio (org.). Ideias de História: tradição e inovação de Maquiavel a Herder. Londrina: Eduel, 2007.

; MUNHOZ, Sidnei J. (orgs.). Historiadores de nosso tempo. São Paulo: Alameda, 2010.

MOMIGLIANO, Arnaldo. As raízes clássicas da historiografia moderna. Bauru: Edusc, 2004.

ROHRBACHER, David. The historians of Late Antiquity. London: Routledge, 2003. 
RÜSEN, Jörn (org.). Western historical thinking: an intercultural debate. New York: Berghahn Books, 2002.

WANG, Q. Edward; IGGERS, Georg G. (eds.). Turning points in historiography: a cross cultural perspective. Rochester: The University of Rochester Press, 2002. 